\title{
La Necropoli de Misincinis Tavagnacco
}

\section{Cécile Le Carlier de Veslud}

\section{OpenEdition}

\section{Journals}

Édition électronique

URL : http://journals.openedition.org/rao/951

DOI : 10.4000/rao.951

ISBN : 978-2-7535-1609-0

ISSN : 1775-3732

Éditeur

Presses universitaires de Rennes

Édition imprimée

Date de publication : 31 décembre 2009

Pagination : 315

ISBN : 978-2-7535-1086-9

ISSN : 0767-709X

\section{Référence électronique}

Cécile Le Carlier de Veslud, «La Necropoli de Misincinis Tavagnacco», Revue archéologique de l'Ouest [En ligne], 26 | 2009, mis en ligne le 31 décembre 2011, consulté le 08 décembre 2020. URL : http:// journals.openedition.org/rao/951 ; DOI : https://doi.org/10.4000/rao.951 
Giumlia-Mair, A., 2003 - La Necropoli de Misincinis Tavagnacco, Arti Grafiche Friulane SpA, (3 vol.), 150 p.

Cette publication est consacrée à l'étude de l'importante nécropole à incinération de Misincinis, située à proximité du village de Paularo, dans la vallée du Chiarso qui entaille les premiers contreforts des Alpes friulanes au nord-est de la plaine du Pô. Datée de l'âge du Fer, elle présente la précieuse particularité d'avoir été entièrement fouillée et d'avoir suscité de nombreuses études sur son mobilier et son environnement. L'ouvrage présenté ici est constitué de trois volumes, le premier (Dopo lo scavo) étant consacré aux résultats de la campagne de fouille (1995-1997).

Le deuxième (La metallurgia nell'età del ferro) traite de la fabrication et de la composition de certains objets métalliques déposés dans les tombes. Dans un premier temps, après une présentation typologique des fibules, l'auteur présente l'aire de répartition de ces objets en Italie du nord, dans un espace situé entre le nord-ouest de la plaine du Pô, les Alpes orientales et les territoires balkaniques septentrionaux. L'auteur s'interroge alors sur l'origine du métal de ces objets. En répertoriant les mines de cuivre des Alpes, on ne peut que se rendre compte de la proximité de ces sites avec les mines. S'en suit une discussion concernant la nature des minerais et leur mode d'exploitation, ainsi que sur les techniques métallurgiques, en prenant exemple des découvertes faites sur d'autres sites alpins, tel que celui de Mitterberg en Autriche. Enfin, vient l'étude des fibules elles-mêmes, analysées par activation neutronique et par microscopie électronique à balayage. Il en résulte que ce sont des objets composés par un alliage à $\mathrm{Cu} / \mathrm{Sn}$ majoritaires avec une teneur en étain variant de 8 à $12 \%$. Le plomb peut être présent en faible quantité, jusqu’à $3 \%$. Des reconstitutions expérimentales ont été réalisées afin de reproduire le même métal et de retrouver les gestes techniques des bronziers ayant conduit à la fabrication des fibules, de certains pendentifs anthropomorphes ou de chaînettes.

Le troisième volume (L'ambiente e l'uomo nell'età del ferro) est consacré à l'interaction entre l'homme et son environnement. Il s'intéresse aux restes végétaux et humains retrouvés dans les tombes. Ceci a permis de reconstituer le paysage végétal, composé essentiellement de hêtres et de pomoïdés dans un environnement montagnard. L'étude des restes osseux conduit l'auteur à discuter des gestes funéraires mais permet également un recensement des individus par genre et classe d'age ainsi que l'obtention de quelques données concernant d'éventuelles pathologies. Les analyses chimiques de ces mêmes restes permettent également de proposer des hypothèses quant à la nutrition de cette population.

Cécile Le Carlier de VesLud

Jean Trinquier et Christophe Vendries (dir.), 2009 - Chasses antiques. Pratiques et représentations dans le monde gréco-romain (IIt siècle av. IV siècle apr. J.-C.), Actes du colloque international, université de Rennes 2, 20-21 septembre 2007, Rennes, PUR, coll. "Archéologie \& Culture », 276 p. 28 x 22 cm, ill. n. \& b., VIII pl. coul., orientations bibliographiques, indices, résumés (ISBN 978-2-7535-0835-4; $24 €$ ). (publication soutenue par la Fondation de la Maison de la Chasse et de la Nature).

Ce recueil évoque le statut du chasseur et l'art de la chasse dans la Grèce hellénistique et dans le monde romain, avec ses codes et ses rites, son rôle économique et ses aspects juridiques et religieux. Dans leur avant-propos, les responsables du colloque posent d'abord la question du rapport de l'homme avec le monde sauvage, puis s'interrogent sur la place de la chasse dans la hiérarchie des activités sociales à l'époque romaine et sur le dialogue entre nature et culture. Treize contributions sont réparties en trois parties.

La chasse et le pouvoir

Dans une réflexion sur "L'empereur romain et la chasse ", Patrick Le Roux montre que la chasse, habituellement peu prisée des empereurs romains, a compensé, pour Hadrien, l'absence de pratique guerrière. Il rend sa référence militaire à la statue équestre lacunaire de Misène figurant Domitien et remployée avec la tête de Nerva, que S. L. Tuck considérait comme une statue d'empereur chasseur.

Christophe Badel observe " La noblesse romaine et la chasse " : pour l'aristocratie romaine, la chasse est un loisir courant, qui met en œuvre la résistance, la patience et l'endurance, et non une activité ennoblissante, identitaire, faisant appel aux valeurs civiques et à la noblesse de caractère.

François Baratte évoque "La chasse dans l'iconographie des sarcophages, signe social ou valeur funéraire? ». Parmi les quelque 250 sarcophages à scènes de chasse recensés, il est souvent difficile de distinguer les scènes mythologiques des figurations réalistes et des spectacles de venatores, de faire la part entre le puissant symbolisme du triomphe 